\title{
Suplementação com sal mineral proteinado para bezerros mantidos em pastagem de capim Mombaça, no inverno ${ }^{1}$
}

\section{Protein and mineral supplementation for calves grazing a Mombaça pasture during the winter}

\author{
Fernanda Barros Moreira ${ }^{2 *}$; Ivone Yurika Mizubuti ${ }^{3}$; Ivanor Nunes do Prado ${ }^{4}$; \\ Makoto Matsushita ${ }^{4}$; Marcelo Takeo Matsubara ${ }^{5}$; Romerson Dognani ${ }^{5}$
}

Resumo

O objetivo deste trabalho foi avaliar o efeito da suplementação protéica sobre o desempenho de bezerros de corte mantidos em pastagem de capim Mombaça, no período do inverno. Foram utilizados 30 bezerros, da raça Nelore, com peso vivo médio inicial de $191 \mathrm{~kg}$, distribuídos ao acaso em dois tratamentos: suplementação com sal mineral e suplementação com sal mineral proteinado. Foram utilizados dois piquetes de capim Mombaça, com taxa de lotação de $0,75 \mathrm{UA} / \mathrm{ha}$. Para formulação do sal mineral proteinado foram utilizados: farinha de varredura de mandioca, farelo de algodão, uréia/sulfato de amônio na proporção de 10:1, premix mineral e sal comum. Houve perda de peso nos primeiros 28 dias de avaliação, sendo esta perda superior para os animais suplementados com sal mineral proteinado $(-0,13 \mathrm{~kg} / \mathrm{dia})$ em relação aos animais com suplementação mineral $(-0,01 \mathrm{~kg} / \mathrm{dia})$. Avaliando o ganho médio diário durante todo período experimental, não houve diferença entre os tratamentos (média de $0,38 \mathrm{~kg} / \mathrm{dia}$ ). A massa seca média de forragem no período foi de $2545 \mathrm{~kg} \mathrm{MS} / \mathrm{ha}$ e os teores médios de $\mathrm{PB}$ foram de 7,05 e 3,58\% para folhas e colmos, respectivamente.

Palavras chave: Ganho de peso, mandioca, panicum, sal proteinado, uréia

\begin{abstract}
The aim of this work was to evaluate the effect of protein supplementation on the performance of beef calves grazing Mombaça pasture, during the winter. Thirty Nelore calves, $191 \mathrm{~kg}$ initial body weight were split in two treatments: mineral salt supplementation and protein mineral salt supplementation. It was used pastures of Mombaça, with a stocking rate of $0.75 \mathrm{AU} / \mathrm{ha}$. The ingredients used on the protein mineral salt formulation were: cassava meal, cottonseed meal, urea/ammonium sulfate in the 10:1 ratio, mineral premix and salt. There was a weight lost in the first 28 days of the experiment, which was higher for the animals supplemented with protein mineral salt $(-0.13 \mathrm{~kg} /$ day $)$ when compared to the animals with mineral supplementation (-0.01 kg/day). Average daily gain showed no difference during the experimental period (average of $0.38 \mathrm{~kg} /$ day). Available dry mass of forage was $2545 \mathrm{~kg} \mathrm{MS} / \mathrm{ha}$ and protein content was 7.05 and $3.58 \%$ for leaves and stems, respectively.

Key words: Cassava, panicum, protein salt, urea, weight gain

1 Trabalho financiado pela CAPES

2 Professor Doutor, Universidade Estadual de Londrina - UEL, Londrina/PR, Brasil. E-mail: fbmoreira@sercomtel.com.br.

3 Professor Doutor, Universidade Estadual de Londrina - UEL, Londrina/PR, Brasil

4 Professor Doutor, Universidade Estadual de Maringá, Maringá, Paraná, Brasil.

5 Graduandos em Medicina Veterinária, UEL, Londrina/PR.
\end{abstract}

* Autor para correspondência 


\section{Introdução}

O uso de pastagens diferidas no final do verão, para serem utilizadas no período da seca, tem sido uma alternativa de baixo custo, utilizada por alguns produtores de carne bovina. Contudo, muitas vezes, o que se observa é a manutenção ou até mesmo a perda de peso animal quando se utiliza estas pastagens diferidas, mesmo quando existe excedente de forragem (PRADO et al., 2004). Estes resultados podem ser explicados, principalmente, pela queda na qualidade da forragem madura, uma vez que os níveis de proteína bruta e de proteína bruta digestível, assim como a digestibilidade da forragem diminuem em decorrência do envelhecimento da planta (MOREIRA et al., 2004a).

Esses mesmos autores acima citados têm demonstrado que os níveis de proteína bruta de forrageiras tropicais, no período do inverno, apresentam valores inferiores a 7\%. Van Soest (1994) destacou que o teor de proteína bruta da dieta de 7\% é o mínimo para que não haja prejuízo para os microrganismos do rúmen, e, por consequência, queda na digestibilidade da forragem. Quando a dieta não fornece o nível mínimo de 7\% de proteína bruta na matéria seca, a reciclagem da uréia não é suficiente para atender a demanda de nitrogênio pelos microrganismos do rúmen, e o resultado final é a queda no consumo e na digestibilidade da forragem (VAN SOEST, 1994). Outro fator a considerar é o teor de lignina na forragem. $\mathrm{O}$ aumento nos teores de lignina, comum em função do envelhecimento da planta, também poderia levar à diminuição na digestibilidade da forragem, e por, consequencia, prejuízo para o desempenho animal (MINSON, 1990).

Por isso, o uso de suplementos que complementem a quantidade mínima de proteína, necessária para o melhor aproveitamento da forragem disponível, pode resultar em melhor digestibilidade da forragem e, por consequência, melhor desempenho animal. Alguns trabalhos têm confirmado este melhor desempenho animal quando da utilização da suplementação a pasto (SANTOS et al., 2004). No entanto, outros trabalhos têm demonstrado a ausência de efeito positivo sobre o desempenho animal quando da utilização do sal mineral proteinado como suplemento (MOREIRA et al., 2003). Estas diferenças na resposta do animal podem ser decorrentes do tipo de forragem utilizada, da qualidade e massa seca de forragem, do período do ano, do tipo de suplemento protéico, da quantidade consumida do suplemento ou da categoria animal testada.

O objetivo deste trabalho foi estudar o desempenho de bovinos de corte, em crescimento, mantidos em pastagem de capim Mombaça, no período do inverno, suplementados com sal mineral ou sal mineral proteinado, assim como determinar a massa seca e a composição química do capim Mombaça, durante o inverno.

\section{Material e Métodos}

O experimento foi conduzido na Fazenda Ibicatu, localizada no município de Centenário do Sul, região norte do Paraná. O solo da região é do tipo Latossolo vermelho escuro, textura média e o clima é caracterizado como subtropical úmido mesotérmico, conforme descrito pela SEAB - Secretaria da Agricultura e do Abastecimento (PARANA, 1994).

Foram utilizados 30 bezerros, Nelores, com idade inicial média de 8 meses. Os animais foram identificados e distribuídos, ao acaso, em dois tratamentos: 1- Suplementação mineral; 2Suplementação com sal mineral proteinado. Para a formulação do sal mineral proteinado foram utilizados: $60 \%$ de farinha de varredura da mandioca, $15 \%$ de farelo de algodão, $10 \%$ de uréia/sulfato de amônio na proporção de 10:1, 5\% de premix mineral e 10\% de sal comum.

A farinha de varredura da mandioca apresentava $89,18 \%$ de matéria seca (MS), 3,30\% de proteína bruta (PB), 0,20\% de extrato etéreo (EE), 9,80\% de fibra em detergente neutro (FDN) e $85,30 \%$ de carboidratos não fibrosos (CNF). $\mathrm{O}$ farelo de algodão apresentava $89,10 \%$ de MS, $33,18 \%$ de $\mathrm{PB}, 0,81 \%$ 
de EE, 31,40\% de FDN e 30,04\% da CNF. O premix mineral apresentava, para cada $\mathrm{kg}$ do produto, $5 \mathrm{~g} \mathrm{P}$, $56 \mathrm{~g} \mathrm{Ca}, 15 \mathrm{~g} \mathrm{Mg}, 16 \mathrm{~g} \mathrm{~S}, 56 \mathrm{~g} \mathrm{Na}, 2500 \mathrm{mg} \mathrm{Zn}, 650$ $\mathrm{mg} \mathrm{Cu}, 1250 \mathrm{mg} \mathrm{Mn}, 500 \mathrm{mg}$ Fe, $25 \mathrm{mg} \mathrm{Co}, 40 \mathrm{mg}$ I, $15 \mathrm{mg}$ Se e $150 \mathrm{mg}$ F.

Os suplementos eram mantidos constantemente nos cochos de forma que o consumo fosse controlado pelo cloreto de sódio e uréia presentes nos mesmos. A reposição dos suplementos era feita três vezes por semana ou sempre que a quantidade de suplemento nos cochos ficasse diminuída. A estimativa do consumo foi feita através das pesagens do total de suplemento fornecido durante os quatorze dias em que os animais permaneciam em cada piquete e a pesagem das sobras dos cochos obtidas ao final dos quatorze dias quando os animais eram trocados de piquete.

Os animais foram pesados ao início do experimento e a cada 28 dias, totalizando quatro períodos de 28 dias, iniciando em 24 de junho de 2003 e finalizando em 13 de outubro de 2003. No início do experimento, os animais foram desverminados com vermífugo à base de albendazol e o controle da mosca do chifre foi realizado com inseticidas à base de cipermetrina.

Os bezerros foram mantidos em dois piquetes de capim Mombaça (Panicum maximum Jacq. Cv. Mombaça), totalizando uma área de 9,42 ha. Nos piquetes estavam localizados bebedouros com capacidade de $4000 \mathrm{~L}$ e cochos cobertos com comprimento de $5 \mathrm{~m}$ linear. A cada 14 dias, os animais eram alternados de piquete para que a cada pesagem os animais dos dois tratamentos passassem pelos dois piquetes disponíveis. O manejo adotado foi de lotação contínua e carga fixa. A taxa de lotação utilizada foi de $0,75 \mathrm{UA} / \mathrm{ha}$. Esta carga animal foi estipulada em função da massa seca de forragem e de folhas presentes no início do período experimental.

Os piquetes foram diferidos em 10 de maio para serem utilizados a partir de 24 de junho de 2003. Não foi realizada nenhuma adubação de cobertura nos piquetes naquele ano experimental.
Para estimar a quantidade de massa seca dos capins nos piquetes, foram coletadas amostras no início e no final do período experimental. Foram retiradas, por piquete, 6 amostras de $0,25 \mathrm{~m}^{2}$, cortadas $10 \mathrm{~cm}$ acima do solo, conforme técnica descrita por Houlderbaun e Sollenberg (1992). Estas amostras foram separadas em duas porções: uma delas foi separada em lâmina foliar, colmo e material morto e a outra porção não foi feita a separação, sendo mantida todos os componentes da planta. As duas porções foram secas em estufa a $55^{\circ} \mathrm{C}$ por $72 \mathrm{~h}$ e moídas separadamente para análises posteriores.

Para avaliar a composição químico-bromatológica da forragem foram determinados os teores de matéria seca, matéria orgânica, proteína bruta e fibra em detergente neutro das folhas e colmos, conforme descrito por Silva (1990).

Para avaliação de desempenho animal, foi utilizado o delineamento experimental inteiramente casualizado, com 15 repetições por tratamento. A análise estatística dos dados de desempenho animal foi realizada utilizando-se o Sistema de Análises Estatísticas e Genéticas-SAEG (UNIVERSIDADE FEDERAL DE VIÇOSA, 1997). Para comparação entre médias foi utilizado o teste $t$ de Student com $5 \%$ de probabilidade de erro.

\section{Resultados e Discussão}

Não houve diferença $(\mathrm{P}>0,05)$ para peso vivo inicial (PVI) e peso vivo final (PVF) entre os tratamentos. O PVI médio foi de $191 \mathrm{~kg}$ e o PVF médio foi de $233 \mathrm{~kg}$. Durante os primeiros 28 dias de avaliação experimental, houve perda de peso nos dois tratamentos avaliados (Tabela 1).

Esta perda de peso observada nos primeiros 28 dias de avaliação pode ser atribuída à adaptação dos bezerros a esta pastagem, uma vez que, antes do início do experimento, estes animais eram mantidos em uma pastagem de grama estrela roxa (Cynodon plectostachyrus Pilger) rica em folhas, o que possivelmente apresentava-se de melhor qualidade nutricional quando comparada a pastagem utilizada neste experimento. 
Tabela 1. Peso vivo inicial (PVI), peso vivo final (PVF), ganho médio diário (GMD), consumo médio diário de suplemento (CMD) e ganho de peso vivo (GPV) por hectare de bezerros mantidos em pastagem de capim Mombaça, com suplementação mineral ou com sal mineral proteinado.

\begin{tabular}{lccc}
\hline & Sal mineral & Sal mineral proteinado & EPM $^{3}$ \\
\hline PVI (kg) & 191 & 191 & 6,24 \\
PVF (kg) & 236 & 230 & 7,37 \\
$\operatorname{GMD}^{1}(\mathrm{~kg} /$ animal/dia) & $-0,01 \mathrm{a}$ & $-0,13 \mathrm{~b}$ & 0,03 \\
$\mathrm{GMD}^{2}(\mathrm{~kg} / \mathrm{animal} / \mathrm{dia})$ & 0,41 & 0,35 & 0,02 \\
$\mathrm{CMD}(\% \mathrm{do} \mathrm{PV})$ & 0,01 & 0,07 & - \\
$\mathrm{GPV}(\mathrm{kg} / \mathrm{ha}))$ & 73,12 & 62,42 & - \\
\hline
\end{tabular}

${ }^{1}$ GMD entre 24/06/2003 e 22/07/2003; ${ }^{2} \mathrm{GMD}$ entre 24/06/2003 e 13/10/2003; ${ }^{3}$ Erro padrão da média. Letras diferentes na mesma linha são diferentes pelo teste $t$ de Student $(\mathrm{P}<0,05)$.

Durante os primeiros 28 dias de avaliação experimental, os animais suplementados com sal mineral proteinado apresentaram maior perda média diária $(-0,13 \mathrm{~kg} / \mathrm{dia})$ quando comparados aos animais recebendo suplementação mineral $(-0,01 \mathrm{~kg} / \mathrm{dia})$ (Tabela 1).

Moreira et al. (2006), ao testar diferentes níveis de uréia em suplementos protéicos, também observaram menor GMD, nos primeiros 28 dias de suplementação, para os animais suplementados com sal mineral proteinado em comparação à suplementação com sal mineral. Estes autores atribuíram este menor GMD à necessidade de adaptação ao consumo de uréia, uma vez que o GMD foi menor quanto maior o teor de uréia presente nos suplementos.

Outros trabalhos também têm demonstrado que animais suplementados com sal mineral proteinado, durante os primeiros 28 dias de suplementação, apresentam menor ganho de peso quando comparados aos animais suplementados com sal mineral (MOREIRA et al., 2004b). Estes resultados confirmam o resultado obtido neste experimento, onde bezerros recebendo suplementação protéica apresentaram uma redução de 3,36 kg no GMD durante os primeiros 28 dias de suplementação.

Assim, quando da utilização de suplementos ricos em uréia no período da entressafra, deve-se avaliar o tempo de suplementação e a necessidade de adaptação dos animais ao uso da uréia, para que dados mais exatos possam ser realizados quanto à previsão de ganho de peso e a relação custo/benefício do uso destes suplementos.

Considerando todo o período experimental, não houve diferença para o ganho médio diário (GMD) entre os tratamentos. O GMD obtido no experimento, entre o período de 24/06/2003 a 23/10/2003 foi de $0,38 \mathrm{~kg} /$ dia.

Alguns trabalhos têm demonstrado melhor GMD para bovinos suplementados com sal mineral proteinado quando comparados a bovinos suplementados com sal mineral. Moreira et al. (2006) observaram um ganho de $0,82 \mathrm{~kg} /$ dia para novilhos suplementados com sal mineral proteinado, enquanto que os novilhos recebendo sal mineral apresentaram ganho de $0,30 \mathrm{~kg} /$ dia. O sal mineral proteinado utilizado pelos autores acima citados foi semelhante ao utilizado neste experimento.

Outros trabalhos relatam a ausência de efeito positivo do sal mineral proteinado sobre o ganho de peso quando comparado ao sal mineral. Moreira et al. (2003) observaram GMD semelhante entre novilhos suplementados com sal mineral ou com sal mineral proteinado. Estes autores observaram GMD médio entre os tratamentos de $0,17 \mathrm{~kg} / \mathrm{dia}$ para novilhos em crescimento e $0,02 \mathrm{~kg} /$ dia para novilhos em terminação. 
Estes resultados indicam a complexidade de resposta no GMD de bovinos suplementados ou não com sal mineral proteinado no período da seca. A base da alimentação destes animais é o pasto, portanto, fatores como a qualidade e a massa seca da forragem são determinantes no tipo de resposta do animal quando do uso da suplementação com sal mineral proteinado.

Fatores como nível de consumo do sal mineral proteinado também podem interferir na resposta do animal a estes suplementos. Moreira et al. (2004b), ao estudarem diferentes níveis de suplementação com sal mineral proteinado, observaram melhor GMD para novilhos suplementados com sal mineral proteinado $(0,15 \mathrm{~kg} / \mathrm{dia})$ quando o consumo foi de $0,1 \%$ do peso vivo. No entanto, estes autores não observaram diferença no GMD quando o consumo do suplemento ficou em $0,07 \%$ do peso vivo $(0,05 \mathrm{~kg} / \mathrm{dia})$ em comparação ao uso do sal mineral $(0,06 \mathrm{~kg} / \mathrm{dia})$. Neste experimento, o consumo de sal mineral proteinado foi de $0,07 \%$ do peso vivo (Tabela 1 ), o que pode ter contribuído para ausência de efeito positivo do suplemento protéico sobre o GMD dos bezerros.

Alguns trabalhos têm demonstrado o efeito positivo da suplementação a pasto sobre o GMD. Santos et al. (2004) avaliaram diferentes concentrados, fornecidos para consumo de $1 \%$ do peso vivo, para tourinhos de peso vivo inicial de 367 $\mathrm{kg}$, mantidos em pastagem de Brachiaria decumbens, na estação seca. Foi observado melhor GMD para os animais suplementados com concentrado. Estes autores relataram GMD de 0,10 $\mathrm{kg} /$ dia para os tourinhos suplementados com sal mineral e GMD entre os concentrados de $0,91 \mathrm{~kg} /$ dia, sendo que não foi observada diferença entre os concentrados testados.

O GMD obtido durante todo o período experimental foi de $0,38 \mathrm{~kg} / \mathrm{dia}$. Este desempenho animal pode ser atribuído à qualidade da forragem, que apresentava baixos teores de proteína bruta e altos valores de fibra em detergente neutro (Tabela 3), sugerindo assim a pouca digestibilidade do pasto.
No entanto, considerando que o período de avaliação foi o inverno (entressafra), o GMD obtido foi superior ao observado por outros trabalhos no mesmo período de avaliação, quando muitas vezes observa-se até mesmo perda de peso neste período do ano.

Zanetti et al. (2000) observaram perda de 0,10 $\mathrm{kg}$ /dia para animais suplementados com sal mineral e mantidos em pastagem de Brachiária decumbens. Neste trabalho, não foi observada perda de peso durante o período experimental, o que pode ser decorrente da massa seca de forragem estar acima de $2000 \mathrm{~kg} / \mathrm{ha}$ (Tabela 2), valor este estipulado por Minson (1990) como mínimo para que não limite o consumo de forragem pelos animais.

O ganho médio de peso vivo por hectare obtido entre os tratamentos durante o experimento, foi de $67,77 \mathrm{~kg} /$ ha (Tabela 1). O baixo ganho por área obtido foi decorrente do baixo desempenho animal (Tabela 1) e baixa taxa de lotação utilizada, sendo função da reduzida massa seca de forragem observada na pastagem (Tabela 2). Os sistemas de produção a pasto apresentam, durante o período do inverno, baixo ganho de peso individual e por área em função da diminuição da produção forrageira e diminuição da qualidade da pastagem observada para forrageiras tropicais durante o período de inverno.

A massa seca média de forragem no início do período experimental foi de $2245 \mathrm{~kg} \mathrm{MS} / \mathrm{ha}$ (Tabela 2). A massa seca média da forragem estava acima de $2000 \mathrm{~kg} / \mathrm{ha}$. Por outro lado, a massa seca de folhas estava abaixo de $2000 \mathrm{~kg} / \mathrm{ha}$ ( $895 \mathrm{~kg} / \mathrm{ha})$, o que pode ter comprometido a seletividade dos animais, resultando assim no consumo de partes da forragem com menor valor nutritivo, como colmos e material morto, o que resultou no baixo desempenho observado neste experimento.

No final do período experimental, a massa seca média de forragem foi de $2845 \mathrm{~kg} \mathrm{MS} /$ ha (Tabela 2). Esta maior quantidade comparada com o início do experimento foi decorrente da rebrota da forragem observada nos meses de setembro e outubro, quando as temperaturas começam a se elevar e aumenta a quantidade de chuvas nesta região, o que resulta no retorno do crescimento das forrageiras tropicais. 
Tabela 2. Massa seca total, folhas, colmos e material morto na pastagem de capim Mombaça no início (24/06/2003) e final (13/10/2003) do experimento.

\begin{tabular}{lcccc}
\hline Massa seca & Piquete 1 & Piquete 2 & Piquete 1 & Piquete 2 \\
\hline & \multicolumn{2}{c}{ Início do Experimento } & \multicolumn{2}{c}{ Final do Experimento } \\
\hline MS (kg/ha) & 2011 & 2478 & 3096 & 2594 \\
Folhas (kg/ha) & 826 & 965 & 1095 & 1001 \\
Colmos (kg/ha) & 370 & 414 & 389 & 335 \\
Material morto (kg/ha) & 815 & 1099 & 1612 & 1258 \\
\hline
\end{tabular}

A massa seca de folhas no final do período experimental (1048 $\mathrm{kg}$ de MS de folhas/ha) também foi superior ao início do experimento (895 $\mathrm{kg}$ de MS de folhas/ha - Tabela 2), o que confirma o crescimento da forragem observado neste período.

Os teores de matéria seca (MS), matéria orgânica (MO), proteína bruta (PB) e fibra em detergente neutro (FDN) das folhas, colmos e material morto da pastagem de capim Mombaça no início (24/06/ 2003) e final (13/10/2003) do experimento estão apresentados nas tabela 3 e 4 .
Observa-se que houve uma pequena diferença numérica entre os teores de PB das folhas, colmos e material morto dos piquetes 1 e 2 , tanto no início como final do período experimental. No entanto, como os bezerros eram mantidos 14 dias em cada piquete, e, a cada pesagem, os animais dos dois tratamentos passavam pelos dois piquetes, esta diferença no teor de $\mathrm{PB}$ da forragem provavelmente não interferiu no desempenho dos bezerros.

Tabela 3. Teores de matéria seca (MS), matéria orgânica (MO), proteína bruta (PB) e fibra em detergente neutro (FDN) das folhas, colmos e material morto da pastagem de capim Mombaça no início (24/06/2003) do experimento

\begin{tabular}{lcccc}
\hline Piquete 1 & MS (\%) & MO (\% na MS) & PB (\% na MS) & FDN (\% na MS) \\
\hline Folhas & 65,60 & 90,22 & 7,23 & 72,28 \\
Colmos & 68,24 & 93,77 & 3,30 & 83,64 \\
Material morto & 97,90 & 90,59 & 3,08 & 82,48 \\
\hline
\end{tabular}

\begin{tabular}{lcccc}
\hline Piquete 2 & MS (\%) & MO (\% na MS) & PB (\% na MS) & FDN (\% na MS) \\
\hline Folhas & 51,92 & 90,65 & 5,97 & 71,40 \\
Colmos & 56,20 & 92,89 & 2,92 & 79,64 \\
Material morto & 94,75 & 91,96 & 2,61 & 83,47 \\
\hline
\end{tabular}

Considerando a média dos dois piquetes, observase que o teor de PB das folhas no início do experimento era de $6,6 \%$. Este valor é inferior a 7\% na MS, sendo este o mínimo preconizado por Van Soest (1994) para que não haja prejuízo da utilização da forragem por parte dos microrganismos ruminais. Por outro lado, o teor médio de PB dos colmos no início do experimento era de $3,11 \%$. Tendo em vista que os animais podem consumir folhas e colmos, o teor de PB da forragem consumida pelos animais poderia estar abaixo dos $7 \%$, o que confirmaria a necessidade de suplementação protéica para os bezerros mantidos nesta pastagem. 
Tabela 4. Teores de matéria seca (MS), matéria orgânica (MO), proteína bruta (PB) e fibra em detergente neutro (FDN) das folhas, colmos e material morto da pastagem de capim Mombaça no final (13/10/2003) do experimento

\begin{tabular}{lcccc}
\hline Piquete 1 & MS (\%) & MO (\% na MS) & PB (\% na MS) & FDN (\% na MS) \\
\hline Folhas & 37,10 & 86,99 & 8,13 & 74,19 \\
Colmos & 30,10 & 88,24 & 4,32 & 74,10 \\
Material morto & 81,91 & 88,09 & 3,02 & 82,85 \\
\hline
\end{tabular}

\begin{tabular}{lcccc}
\hline Piquete 2 & MS (\%) & MO (\% na MS) & PB (\% na MS) & FDN (\% na MS) \\
\hline Folhas & 37,05 & 84,55 & 6,88 & 77,18 \\
Colmos & 28,26 & 87,31 & 3,80 & 79,02 \\
Material morto & 82,89 & 87,52 & 3,56 & 84,09 \\
\hline
\end{tabular}

Ao comparar os teores de PB e FDN das folhas, colmos e material morto no início e final do período experimental, observa-se que os níveis de PB foram superiores e de FDN foram inferiores no final do período experimental (Tabelas 3 e 4). O final do período experimental ocorreu em outubro, época em que as chuvas já iniciaram e, por conseguinte, a rebrota da forragem. Esta rebrota foi confirmada pela maior massa seca de forragem encontrada no final do período experimental (Tabela 2). Na forragem mais jovem, os teores de PB são maiores e os níveis de fibra são menores (NELSON; MOSER, 1994). No final do período experimental, em função da rebrota, os teores de PB foram superiores e de FDN foram inferiores, justificando os dados obtidos neste experimento.

\section{Conclusões}

Bezerros Nelores mantidos em pastagem de capim Mombaça, no período do inverno, suplementados com sal mineral proteinado, não apresentaram melhor ganho de peso quando comparados a bezerros suplementados com sal mineral, dentro do nível de consumo de sal proteinado de $0,07 \%$ do peso vivo.

Pastagens de capim Mombaça, no período da seca, podem apresentar teores de proteína bruta abaixo do mínimo necessário, podendo comprometer o metabolismo ruminal, o que sugere a necessidade de suplementação protéica nesta fase, desde que haja um consumo mínimo de proteína para que possa manifestar um possível efeito benéfico sobre o desempenho animal.

\section{Referências}

HOLDERBAUN, J. F.; SOLLENBERG, K. H. Canopy structure and nutritive value of limpograss pastures during mid-summer to early autumn. Agronomy Journal, Madison, v. 84, n. 1, p. 11-16, 1992.

MINSON, D. J. Forage in ruminant nutrition. San Diego: Academic Press, 1990.

MOREIRA, F. B.; MIZUBUTI, I. Y.; PRADO, I. N.; ROCHA, M. A.; RIBEIRO, E. L. A.; MATSUBARA, M. T. ; DOGNANI, R.. Níveis de uréia em suplementos protéicos para novilhos mantidos em pastagem de capim Mombaça, no inverno. Acta Scientiarum. Animal Sciences, Maringá, v. 28, n. 1, p. 63-71, 2006.

MOREIRA, F. B.; PRADO, I. N.; CECATO, U.; WADA, F. Y.; MIZUBUTI, I. Y. Forage evaluation, chemical composition, and in vitro digestibility of continuously grazed star grass. Animal Feed Science and Technology, Philadelphia, v. 113, n. 1/4, p. 239-249, 2004a.

MOREIRA, F. B.; PRADO, I. N.; CECATO, U.; WADA, F. Y.; NASCIMENTO, W. G.; SOUZA, N. E. Suplementação com sal mineral proteinado para bovinos de corte, em crescimento e terminação, mantidos em pastagem de grama estrela roxa (Cynodon plectostachyrus Pilger), no inverno. Revista Brasileira de Zootecnia, Viçosa, v. 32, n. 2, p. 449-455, 2003. 
MOREIRA, F. B.; PRADO, I. N.; CECATO, U.; ZEOULA, L. M., WADA, F. Y.; TORII, M. S. Níveis de suplementação com sal mineral proteinado para novilhos Nelore terminados em pastagem no período de baixa produção forrageira. Revista Brasileira de Zootecnia, Viçosa, v. 33, n. 6s, p. 1814-1821, 2004b.

NELSON, C. J.; MOSER, I. E. Plant factors affecting forage quality. In: FAHEY JUNIOR, G. C. (Ed.) Forage quality, evaluation, and utilization. Madison: Wiscosin, 1994. p. 115-154.

PARANÁ. Secretaria da Agricultura e do Abastecimento. Manual técnico do subprograma de manejo e conservação do solo. Curitiba: SEAB, 1994.

PRADO, I. N.; MOREIRA, F. B.; CECATO, U.; WADA, F. Y.; OLIVEIRA, E., REGO, F. C. A. Sistemas para crescimento e terminação de bovinos de corte a pasto: avaliação do desempenho animal e características da forragem. Revista da Sociedade Brasileira de Zootecnia, Viçosa, v. 32, n. 4, p. 955-965, 2004.
SANTOS, E. D. G.; PAULINO, M. F.; VALADARES FILHO, S. C.; LANA, R. P.; QUEIROZ, D. S.; FONSECA, D. M. Terminação de tourinhos Limousin x Nelore em pastagem diferida de Brachiaria decumbens Stapf, durante a estação seca, alimentados com diferentes concentrados. Revista da Sociedade Brasileira de Zootecnia, Viçosa, v. 33, n. 6, p. 1627-1637, 2004.

SILVA, D. J. Análise de alimentos e métodos químicos e biológicos. 2.ed. Viçosa: Imprensa Universitária. 1990.

UNIVERSIDADE FEDERAL DE VIÇOSA SAEG: Sistema para análises estatísticas e genéticas. Versão 7.1. Viçosa: UFV, 1997. (Manual do usuário).

VAN SOEST, P. J. Nutritional ecology of the ruminant. 2.ed. New York: Cornell University Press, 1994.

ZANETTI, M. A.; RESENDE, J. M. L.; SCHALCH, F.; MIOTTO, C. M. Desempenho de novilhos consumindo suplemento mineral proteinado convencional ou com uréia. Revista Brasileira de Zootecnia, Viçosa, v. 29, n. 3 , p.935-939, 2000. 